\title{
Estimativa de energia metabolizável de rações com polpa cítrica em substituição ao milho para tourinhos em terminação ${ }^{1}$
}

\author{
Eduardo Menegueli Pereira², Flávio Augusto Portela Santos 3 , Luiz Gustavo Nussio ${ }^{3}$, Alexandre \\ Mendonça Pedroso ${ }^{2}$, Diogo Fleury Azevedo Costa ${ }^{2}$, Hugo Imaizumi ${ }^{4}$, Carla Maris Machado Bittar ${ }^{3}$ \\ 1 Projeto financiado pela FAPESP. \\ 2 Pós-graduação em Ciência Animal e Pastagem - USP/ESALQ \\ ${ }^{3}$ Depto de Zootecnia - USP/ESALQ, C.P.09 - CEP: 13.418-900 - Piracicaba, SP. \\ ${ }^{4}$ Dr. em Ciência Animal e Pastagem - USP/ESALQ.
}

\begin{abstract}
RESUMO - Avaliou-se a substituição do milho moído fino (MM) por polpa cítrica (PC) em rações para bovinos machos não-castrados terminados em confinamento. As rações continham $70 \%$ de concentrado e $30 \%$ de silagem de cana-de-açúcar e foram formuladas com 0, 50, 75 e 100\% de PC em substituição ao milho. Além dos suplementos energéticos estudados, as rações continham grãos de soja quebrados, uréia, mistura mineral e vitamínica e monensina sódica. Foram utilizados 72 machos Canchim não-castrados, com $318 \mathrm{~kg}$ de PV inicial e 18 meses de idade. O delineamento utilizado foi o de blocos casualizados e a duração do período experimental foi de 130 dias - 14 para adaptação e 116 para a coleta de dados (divididos em quatro subperíodos). A eficiência alimentar e a energia líquida de mantença e de ganho foram maiores nos animais alimentados com a dieta formulada com 50\% de PC em comparação àquela isenta de polpa. O ganho de peso diário e o consumo de MS (IMS) obtidos com as dietas com 75 e 100\% de PC foram inferiores aos encontrados com 50\% de substituição. A espessura de gordura e o rendimento de carcaça não foram influenciados pelos níveis de substituição do milho por polpa cítrica. Considerando os dados obtidos, os dois modelos, NRC (2001) e NRC (1996), subestimam o valor energético da PC em comparação ao MM.
\end{abstract}

Palavras-chave: energia, subprodutos, terminação de bovinos

\section{Estimation of metabolizable energy in diets with varying ratios of dried citrus pulp plus corn fed to finishing Canchim bulls}

\begin{abstract}
Seventy-two finishing Canchim bulls averaging $318 \mathrm{~kg}$ of initial body weight and 18 months of age were assigned to a completely randomized block design to evaluate the effects of replacing ground corn (GC) with dried citrus pulp (CP) on average daily weight gain, dry matter intake, feed efficiency, carcass yield, and Longissimus dorsi fat thickness. Diets contained forage (sugarcane silage) to concentrate ratio of $30: 70$ and the following levels of CP and GC: $100 \%$ GC (CP0), $50 \% \mathrm{GC}+50 \% \mathrm{CP}(\mathrm{CP} 50), 25 \% \mathrm{GC}+75 \% \mathrm{CP}(\mathrm{CP} 75)$, or 100\% CP (CP100). The experiment lasted 130 days with 14 days for diet adaptation and 116 days for data and sample collection. Feed efficiency and net energy for maintenance and gain were all greatest on CP50 than on CP0 diet. Daily weight gain and DM intake were lower on CP100 and CP75 compared to CP50. No significant differences were observed for fat thickness and carcass yield across treatments. Based on the actual data, both the NRC (1996) and NRC (2001) models underestimated the energy value of CP compared to GC.
\end{abstract}

Key Words: byproducts, energy, finishing cattle

\section{Introdução}

No Brasil, a crescente produção de grãos e hortifrutigranjeiros tem aumentado nos últimos anos a disponibilidade não apenas de grãos de cereais, mas também de subprodutos possíveis de utilização na alimentação de bovinos de corte. A polpa cítrica (PC), um subproduto da fabricação de suco concentrado, é constituída de cascas, sementes, bagaço e frutas descartadas. Nos últimos anos, tem sido utilizada como potencial alterna- tiva ao milho em rações para bovinos em confinamento (Santos et al., 2004).

Uma das vantagens da polpa cítrica é a fermentação ruminal, que a torna um produto intermediário entre volumosos e concentrados. Diferentemente dos grãos de cereais, como milho e sorgo, a PC não contém teores significativos de amido, mas é rica em açúcares solúveis ( $25 \%$ da MS), pectina (25\% da MS) e fibra altamente digestível (23\% da MS). A pectina faz parte da estrutura da parede celular dos vegetais e é quase totalmente (90-100\%) degradável no 
rúmen (Nocek \& Tamminga, 1991). Segundo Van Soest et al. (1991), a pectina é o carboidrato complexo de mais rápida degradação ruminal, podendo apresentar digestibilidade de 30 a 50\%/hora (Chesson \& Monro, 1982; Sniffen, 1988). Estes valores são bem superiores aos do amido de milho, que podem variar de 10 a $35 \%$ /hora nas suas diversas formas de processamento (NRC, 1996).

Trabalhos de substituição de milho por PC em rações com silagem de cana-de-açúcar não foram encontrados na literatura. Portanto, neste trabalho, avaliou-se a substituição parcial ou total do milho moído fino (MM) por PC em rações com $70 \%$ de concentrado e $30 \%$ de silagem de canade-açúcar para bovinos em terminação.

\section{Material e Métodos}

O experimento foi realizado nas instalações do Departamento de Zootecnia da USP-ESALQ. Foram utilizados 72 machos Canchim não-castrados (318 kg de PV inicial e 18 meses de idade) alojados em 24 baias ( 3 x $11 \mathrm{~m}$ ) cobertas (três animais por baia) com piso de concreto. O período experimental teve duração de 130 dias, sendo 14 de adaptação e 116 para coleta de dados, divididos em quatro subperíodos de 29 dias. Os animais foram everminados com produto de princípio ativo Abamectina e receberam dose injetável de complexo vitamínico ADE nos dias 0 e 60 do período experimental.

Foram comparados quatro tratamentos com rações formuladas com $0,50,75$ e $100 \%$ de polpa cítrica em substituição ao milho (Tabela 1 ).
As rações continham $30 \%$ de silagem de cana-deaçúcar tratada com aditivo microbiano Lactobacillus buchneri 50788 (Lalsil ${ }^{\circledR}$ ) e $70 \%$ de concentrado na MS e foram formuladas para serem isoprotéicas e atenderem às exigências em PDR e proteína metabolizável dos animais, de acordo com o NRC (1996) nível 1. A polpa cítrica utilizada durante a fase de adaptação dos animais continha $6,5 \%$ de $\mathrm{PB}$, sendo as rações experimentais formuladas com base na análise bromatológica deste material. Ao longo do experimento, foram comprados outros três lotes ou partidas de polpa cítrica, analisadas apenas ao término do experimento e com valor médio de $7,7 \%$, o que resultou em rações contendo teores crescentes de PB com a inclusão de PC. As rações, apesar de não terem sido isoprotéicas, como planejado, atendiam às exigências de PDR e proteína metabolizável dos animais

Foram utilizados dois compostos minerais distintos, um para a dieta isenta de PC e outro para aquelas com PC, com o objetivo de suprir as exigências minerais, especialmente de cálcio e fósforo, dos animais.

A quantidade de alimento fornecida na forma de ração completa foi ajustada diariamente para manter, no máximo, $5 \%$ de sobras. As sobras eram retiradas a cada dois dias e pesadas para avaliação do consumo de alimento (por baia), que foi calculado como a diferença entre o fornecido e a sobra.

Os animais foram pesados após jejum de 12 horas a cada 29 dias e, a partir dos dados de ganho de peso diário (GPD) e do CMS (consumo de MS), calculou-se a eficiência

Tabela 1 - Composição das rações experimentais

Table 1 - Ingredient composition of the experimental diets

\begin{tabular}{|c|c|c|c|c|}
\hline \multirow[b]{2}{*}{$\begin{array}{l}\text { Ingrediente ( } \% \text { da } \mathrm{MS}) \\
\text { Ingredient }(\% \mathrm{DM})\end{array}$} & \multicolumn{4}{|c|}{$\begin{array}{l}\text { Nível de substituição (\%) } \\
\text { Proportion of dried citrus pulp (\%) }\end{array}$} \\
\hline & 0 & 50 & 75 & 100 \\
\hline Silagem de cana-de-açúcar (Sugarcane silage) & 30,6 & 30,6 & 30,6 & 30,6 \\
\hline Milho moído (Ground corn) & 55,9 & 27,9 & 14,0 & - \\
\hline Polpa cítrica (Citrus pulp) & - & 27,9 & 42,0 & 55,5 \\
\hline Soja grão quebrada (Cracked soybean grain) & 10,4 & 10,4 & 10,4 & 10,4 \\
\hline Mineral $^{\mathrm{a}}$ (Mineral) & 1,6 & 1,6 & 1,6 & 1,6 \\
\hline Uréia (Urea) & 0,96 & 1,23 & 1,40 & 1,55 \\
\hline Calcário (Limestone) & 0,54 & - & - & - \\
\hline \multicolumn{5}{|l|}{$\begin{array}{l}\text { Composição }(\% \mathrm{MS})^{\mathrm{b}} \\
\text { Composition }(\% \quad D M)\end{array}$} \\
\hline $\mathrm{PB}(C P)$ & 13,0 & 13,4 & 13,5 & 13,7 \\
\hline $\mathrm{FDN}(N D F)$ & 26 & 30 & 32 & 34 \\
\hline NDT $(T D N)$ & 79 & 76 & 74 & 72 \\
\hline
\end{tabular}

a Composição mineral (Mineral composition): Composição mineral: K - 7\%; Rumensin ${ }^{\circledR}-1,75 \%$; e (por kg): Cu - 600 mg; - 36 mg; Se - 9 mg; Zn - 3.000 mg; vit. A - 250.000 UI; vit. D - 20.000 UI; vit. E - 1.800 UI; Com $30 \%$ de Ca; $5 \%$ de P; e $5 \%$ de S para tratamento $0 ; 12 \%$ de Ca; $10 \%$ de P; $7 \%$ de S para as rações com 50,75 e $100 \%$ de PC.

b Valores obtidos com base na análise bromatológica e estimados pelo NRC (1996) nível 1 (Values obtained by chemical composition and estimated by NRC (1996) level 1). 
alimentar, como a relação GPD/CMS. Durante as pesagens, foram realizados monitoramentos in vivo da espessura de gordura subcutânea, por meio de ultra-sonografia (Perkins et al., 1992). O transdutor foi disposto perpendicularmente ao músculo Longissimus dorsi, entre a 12 e a 13 a costela, no terço distal da imagem do músculo. $\mathrm{O}$ equipamento de ultra-sonografia utilizado foi o PIEMEDICAL Scanner 200 VET com imagem em tempo real, transdutor de 3,5 MHz, com $18 \mathrm{~cm}$ e uma guia acústica para o acoplamento do transdutor ao animal.

Para avaliação do rendimento de carcaça, calculado com base no peso vivo de abate, foram abatidos 28 animais (7 animais/tratamento) e, após o abate, foram mensurados os pesos da meia-carcaça quente.

Semanalmente, subamostras dos ingredientes utilizados nas rações foram coletadas e congeladas a $-10^{\circ} \mathrm{C}$. Amostras da silagem foram secas a $105^{\circ} \mathrm{C}$ para determinação do teor de MS e ajuste semanal da composição das rações. As subamostras de alimento foram descongeladas e secas em estufas de ventilação forçada $\left(55^{\circ} \mathrm{C}\right)$ por 72 horas para formação de uma única amostra de cada ingrediente. Essas amostras foram trituradas em moinhos tipo Willey com peneiras de $1 \mathrm{e} 2 \mathrm{~mm}$ e analisadas quanto aos teores de MS, segundo metodologias descritas por Silva \& Queiroz (2002). Foram determinados ainda os teores de cinzas, EE e PB, de acordo com a AOAC (1990), e os de FDN e FDA, conforme recomendações de Van Soest et al. (1991). As concentrações de NDT das rações foram calculadas de acordo com o NRC (2001). A granulometria do milho moído (MM) foi determinada antes do início do experimento, conforme metodologia proposta por Yu et al. (1998), para verificar se ingrediente estava dentro do padrão de granulometria adotado como fino (tamanho médio de partículas de $1,2 \mathrm{~mm}$ ).

Adotou-se o delineamento em blocos completos casualizados, com os animais distribuídos de acordo com o peso vivo inicial. Os dados foram analisados utilizando-se o procedimento MIXED do pacote estatístico SAS (1999) versão 8 para Windows. As médias para os tratamentos foram obtidas pelo método dos quadrados mínimos (LSMEANS). Para todos os parâmetros analisados, a baia foi utilizada como unidade experimentale, para acabamento de gordura, apenas os dados do último período foram utilizados para análise. Apenas para a análise dos dados de rendimento de carcaça, o animal foi considerado a unidade experimental. Foram realizadas análises por contraste para verificar a existência de diferença entre as rações com $0 \mathrm{e}$ $50 \%$ de PC. Aplicou-se análise de contraste também com a finalidade de verificar a ocorrência de efeito linear ou desvio de linearidade dentro dos tratamentos com PC. Durante a análise, utilizou-se o nível de 5\% de probabilidade como significativo e até $10 \%$ como tendência. Todos os dados foram testados para verificar a distribuição normal dos erros, utilizando-se o procedimento UNIVARIATE (SAS, 1999). Os dados que apresentaram erros fora do intervalo entre \pm 3 desvios foram arbitrariamente descartados da análise estatística.

A partir dos dados de CMS e GPD obtidos no experimento, foram calculados os valores de energia líquida das rações utilizando-se as fórmulas propostas por Zinn \& Shen (1998) com o objetivo de comparar o resultado encontrado com o previsto pelo sistema NRC (1996) nível 1. Primeiramente, foram calculadas as exigências de ganho $\left(\mathrm{E}_{\mathrm{g}}\right)$ e de mantença $\left(\mathrm{E}_{\mathrm{m}}\right)$ dos animais por meio das fórmulas $1 \mathrm{e} 2$, respectivamente. Calculadas as exigências energéticas relacionadas aos ganhos de peso vivo ( $\mathrm{kg} / \mathrm{dia})$ e aos pesos metabólicos $(\mathrm{kg})$ dos animais durante os quatro períodos experimentais, calculou-se a energia líquida das rações (Mcal/kg de MS) para mantença $\left(\mathrm{EL}_{\mathrm{m}}\right)$ e ganho $\left(\mathrm{EL}_{\mathrm{g}}\right)$ utilizando-se as fórmulas 3 e 4.

$$
\begin{gathered}
\mathrm{E}_{\mathrm{g}}=\left[0,0493 \mathrm{PV}^{0,75}\right] \mathrm{GPD}^{1,097} ;(\mathrm{NRC}, 1984) \\
\mathrm{E}_{\mathrm{m}}=0,077 \mathrm{PV}^{0,75} ;(\text { Lofgreen \& Garrett, } 1968 ; \\
\text { citados por Zinn \& Shen, 1998) } \\
\left.\mathrm{EL}_{\mathrm{m}}=\left(-\mathrm{b}-\left(\left(\mathrm{b}^{2}\right)-(4 \mathrm{ac})\right)^{0,5}\right)\right) /(2 \mathrm{a}) ;(\text { Zinn \& Shen, } \\
1998) \\
\mathrm{a}=-0,877 \mathrm{CMS} \\
\mathrm{b}=0,877 \mathrm{E}_{\mathrm{m}}+0,41 \mathrm{CMS}+\mathrm{E}_{\mathrm{g}} \\
\mathrm{c}=-0,41 \mathrm{E}_{\mathrm{m}} \\
\mathrm{EL}_{\mathrm{g}}=0,877 \mathrm{EL}_{\mathrm{m}}-0,41 ;(\text { Zinn \& Shen, } 1998)
\end{gathered}
$$

em que: $E_{g}=$ exigência de energia para ganho (Mcal/dia); $\mathrm{E}_{\mathrm{m}}=$ exigência de energia para mantença $(\mathrm{Mcal} / \mathrm{dia}) ; \mathrm{EL}_{\mathrm{m}}=$ energia líqüida de mantença (Mcal $/ \mathrm{kg}$ de $\mathrm{MS}$ ); $\mathrm{EL}_{\mathrm{g}}=$ energia líquida de ganho (Mcal/kg de MS).

Como não foi possível obter os dados de consumo individual, utilizaram-se para análise estatística os dados médios obtidos por baia, ou seja, dados médios de CMS, GPD, PV e idade dos quatro subperíodos avaliados para composição dos dados para o modelo NRC (1996) nível 1.

Foram calculadas as relações entre concentração de energia observada:energia esperada. A energia esperada foi calculada pela metodologia do NRC (1996), utilizando-se o NDT da ração para o cálculo. Os resultados da análise bromatológica dos ingredientes das rações foram utilizados para o cálculo de NDT por meio do NRC (2001).

Efetuou-se ainda o cálculo da energia metabolizável observada da PC (EM polpa $)$ pelo método da substituição 
(Zinn et al., 2002), que pode ser utilizado apenas quando a única alteração de fonte de energia dentro do experimento é o ingrediente testado, o que garante maior acurácia em comparação aos levantamentos de subtração tabular. O método de substituição permite estimar a EM do ingrediente testado, mostrando se seu nível de energia é superior ou inferior. Neste experimento, o ingrediente controle utilizado foi o MM por ser um alimento largamente testado, com grande número de estudos na literatura, o que oferece maior confiabilidade. O valor de EM do milho considerado foi de 3,19 Mcal/kg de MS, obtido por meio das fórmulas do NRC (1996), com base no NDT estimado. O NDT foi estimado conforme NRC (2001) com os dados da análise bromatológica do milho. Para aplicação do método de substituição, foram calculados os valores de EM das rações $\left(\mathrm{EM}_{\text {ração }}, \mathrm{Mcal} / \mathrm{kg}\right.$

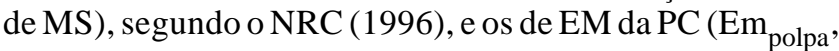
$\mathrm{Mcal} / \mathrm{kg}$ de MS), utilizando-se as fórmulas:

(5) $\mathrm{EM}_{\text {ração }}=\left(\mathrm{EL}_{\mathrm{m}}+0,696\right) / 0,91 ;(\mathrm{NRC}, 1996)$;

(6) $\mathrm{EM}_{\text {polpa }}=[(\mathrm{EM}$ ração testada $-\mathrm{EM}$ ração controle $) /$ $\%$ de polpa nas rações] + 3,19; (Zinn et al., 2002)

\section{Resultados e Discussão}

A composição químico-bromatológica dos ingredientes das rações é apresentada na Tabela 2. A silagem de canade-açúcar com aditivo microbiano Lactobacillus buchneri 50788 (Lalsil ${ }^{\circledR}$ ) apresentou bom valor energético, com 61,16\% de NDT. Segundo Pedroso et al. (2004), o valor de NDT para este volumoso deve situar em torno de 55-58\%.

Os teores de NDT nas tabelas do NRC (1996) são de $90 \%$ para milho quebrado, $88 \%$ para milho moído e $93 \%$ para milho floculado e para a silagem de grão úmido. Assim como neste experimento, os valores de NDT dos alimentos na edição mais recente do NRC para bovinos leiteiros (NRC, 2001) foram calculados pela fórmula de Weiss (1992), sendo descritos valores de $85 \%$ para milho quebrado, $88,7 \%$ para milho moído e $91,7 \%$ para milho floculado. O valor de NDT do milho moído fino obtido neste estudo é próximo ao descrito pelo NRC (1996, 2001).

$\mathrm{O}$ teor de NDT estimado pela metodologia do NRC (2001) para a PC foi de 76,62\%, enquanto os valores propostos pelo NRC $(1996 ; 2001)$ foram 82 e $78,9 \%$, respectivamente, que sugerem que a substituição de milho por PC em rações para bovinos de corte, como neste experimento, deveria prejudicar o desempenho animal.

Os dados de CMS e desempenho animal são apresentados na Tabela 3. Os valores de CMS (9,78 a 10,85 kg/d) obtidos neste estudo foram superiores ao predito pelo NRC (1996) e indicam que, provavelmente, houve crescimento compensatório. Os animais utilizados permaneceram em pastagens com restrição quantitativa e qualitativa, com ganhos de peso muito baixos ou nulos no período da seca, que antecedeu o experimento.

O crescimento compensatório é resultado de taxas de ganho mais elevadas que o próprio crescimento contínuo após períodos de restrição alimentar e, de modo geral, é acompanhado de aumento no consumo de MS. Segundo Lawrence \& Fowler (1997), este aumento no consumo de MS seria decorrente do menor enchimento ruminal por estes animais no início da realimentação.

Aumento no consumo em relação ao PV indica que maior proporção de alimento foi utilizada para ganho. Este efeito foi observado nos dois períodos iniciais do experimento, quando a CMS variou de 2,59 a 3,06\% do PV (Figura 1), resultando, posteriormente, em redução abrupta. O NRC (1996), apesar de ressaltar o efeito da restrição alimentar no consumo de alimentos, não incluiu no modelo de ingestão nenhum fator que justifique o crescimento compensatório. O programa inclui a diminuição nas exigências de mantença, a partir do escore corporal do animal, diminuindo em $5 \%$ as exigências a cada grau abaixo do valor médio 5 .

A substituição de $50 \%$ de milho por PC não alterou $(\mathrm{P}>0,05)$ o consumo de MS pelos animais. Entretanto, a substituição de 75 e $100 \%$ provocou redução linear $(\mathrm{P}<0,05)$

Tabela 2 - Composição químico-bromatológica dos ingredientes (\% MS) Table 2 - Ingredient chemical composition (\% DM)

\begin{tabular}{|c|c|c|c|c|}
\hline $\begin{array}{l}\text { Item } \\
\text { Item }\end{array}$ & $\begin{array}{l}\text { Silagem de cana } \\
\text { Sugarcane silage }\end{array}$ & $\begin{array}{c}\text { Milho moído } \\
\text { Ground corn }\end{array}$ & $\begin{array}{c}\text { Soja grão } \\
\text { Soybean grain }\end{array}$ & $\begin{array}{c}\text { Polpa cítrica } \\
\text { Citrus pulp }\end{array}$ \\
\hline $\operatorname{MS}(D M)$ & 29,50 & 90,04 & 93,49 & 92,62 \\
\hline $\mathrm{PB}(C P)$ & 3,42 & 9,44 & 36,40 & 7,77 \\
\hline $\mathrm{EE}$ & 1,14 & 6,82 & 18,49 & 2,37 \\
\hline Cinzas (Ash) & 3,48 & 1,62 & 5,36 & 7,44 \\
\hline $\mathrm{FDN}(N D F)$ & 60,86 & 9,55 & 21,34 & 23,43 \\
\hline FDA $(A D F)$ & 38,67 & 4,68 & 15,64 & 22,15 \\
\hline $\operatorname{NDT}(T D N)^{\mathrm{a}}$ & 61,16 & 88,29 & 100,12 & 76,62 \\
\hline
\end{tabular}

\footnotetext{
a Calculado de acordo com metodologia proposta pelo NRC (2001).
}

a Estimated according to the NRC (2001) model. 
Tabela 3 - Efeito dos tratamentos no desempenho animal

Table 3 - Effect of increasing levels of dried citrus pulp on animal performance

\begin{tabular}{|c|c|c|c|c|c|}
\hline \multirow[t]{2}{*}{$\begin{array}{l}\text { Item } \\
\text { Item }\end{array}$} & \multicolumn{4}{|c|}{$\begin{array}{l}\text { Nível de substituição, \% } \\
\text { Proportion of dried citrus pulp, \% }\end{array}$} & \multirow[t]{2}{*}{$\begin{array}{c}\mathrm{EPM} \\
S E M\end{array}$} \\
\hline & 0 & 50 & 75 & 100 & \\
\hline Baias por tratamento (Pens per treatment) & 6 & 6 & 6 & 6 & \\
\hline PV inicial, $\mathrm{kg}$ (Initial $B W, \mathrm{~kg}$ ) & 317,5 & 319,2 & 318,8 & 317,2 & \\
\hline PV final, $\mathrm{kg}$ (Final $B W, \mathrm{~kg}$ ) & 506,0 & 526,4 & 504,9 & 493,4 & \\
\hline $\mathrm{GPD}, \mathrm{kg} / \mathrm{dia}^{\mathrm{a}}(A D G, \mathrm{~kg} / \mathrm{d})$ & 1,59 & 1,72 & 1,55 & 1,48 & 0,074 \\
\hline $\mathrm{CMS}, \mathrm{kg} / \mathrm{dia}^{\mathrm{a}}(D M I, \mathrm{~kg} / \mathrm{d})$ & 10,83 & 10,85 & 10,39 & 9,78 & 0,283 \\
\hline Consumo de FDN, $\mathrm{kg}$ de MS/dia ${ }^{\mathrm{b}}$ (NDF intake, $\mathrm{kg}$ of $D M / \mathrm{d}$ ) & 2,82 & 3,24 & 3,33 & 3,33 & 0,092 \\
\hline Eficiência alimentar ${ }^{\mathrm{c}}$ (Feed efficiency) & 0,147 & 0,159 & 0,149 & 0,152 & 0,006 \\
\hline Espessura de gordura, mm (Fat thickness, mm) & 3,89 & 4,15 & 4,15 & 4,16 & 0,136 \\
\hline Rendimento de carcaça, \% (Cascass yield, \%) & 55,8 & 58,2 & 57,3 & 57,3 & 1,157 \\
\hline
\end{tabular}

a Efeito linear de polpa cítrica, $\mathrm{P}<0,05$.

a Linear effect of citrus pulp, $P<0.05$.

b 0 vs $50 \%$ de $P C, P<0,05$.

c 0 vs $50 \%$ de $P C, P<0,10$.

no consumo de MS, principalmente nos dois primeiros períodos experimentais (Figura 1).

O NRC (1996) estima o CMS com base na concentração de $\mathrm{EL}_{\mathrm{m}}$ da ração, com ajustes para determinados fatores, como teor de gordura na carcaça, grupo racial, uso de ionóforo, implante com agente anabolizante, temperatura ambiente e presença de lama. Em decorrência do menor valor energético da $\mathrm{PC}$ em comparação ao milho sugerido nas tabelas do NRC (1996), este programa estima consumo de MS maior em dietas com PC em comparação ao MM, o que não foi observado neste trabalho.

Em rações com teores elevados de concentrado ( 85 a 93\%) para bovinos em terminação, a substituição parcial de grãos de cereais, como milho, por subprodutos ricos em fibra de alta digestibilidade, como farelo de glúten de milho e farelo de trigo, tem causado efeitos positivos no consumo de MS, atribuídos ao possível efeito positivo da redução do teor de amido e do concomitante aumento no teor de fibra, resultando em manutenção do $\mathrm{pH}$ ruminal (Santos et al., 2004). O padrão de fermentação da PC difere do padrão das fontes de cereais, visto que este subproduto não contém amido e é rico em pectina e fibra digestível, propiciando padrão de fermentação mais parecido ao de forragens; ocorre uma produção incipiente de lactato e relação acetato:propionato maior que na fermentação de fontes ricas em amido (Fegeros et al., 1995). Portanto, esperava-se efeito positivo da PC no ambiente ruminal e, conseqüentemente, efeito positivo no consumo de MS.

Entretanto, em rações com 50\% (Prado et al., 2000) ou $20 \%$ (Henrique et al. 2004) de silagem de milho, a substituição parcial ou total do milho moído por PC não afetou o consumo de MS. Neste estudo, quando incluída em níveis superiores a $50 \%$, a PC reduziu o consumo de MS. Esta diferença nos resultados em relação aos revisados por

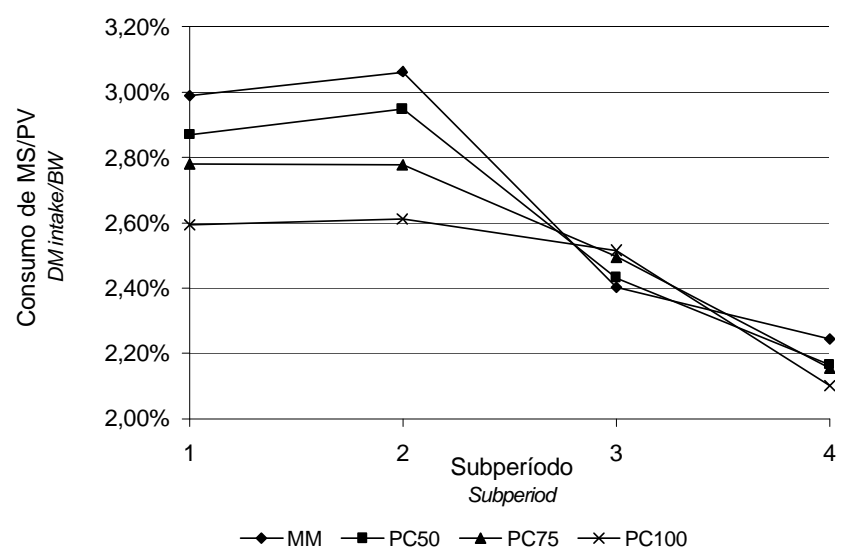

Figura 1 - Porcentagem da MS ingerida em relação ao peso vivo. Figure 1 - DM intake percentage variation related to body weight.

Santos et al. (2004) com farelo de glúten de milho ou farelo de trigo pode ser explicada por dois fatores: a) neste estudo, a ração continha $30 \%$ de forragem, enquanto, nos experimentos analisados por Santos et al. (2004), foram adotados níveis de 7 a $15 \%$ de forragem. Neste caso, o $\mathrm{pH}$ ruminal provavelmente não foi crítico a ponto de haver efeito benéfico com a redução no teor de amido e aumento no teor de fibra; b) a inclusão de altos teores de $\mathrm{PC}$ na ração pode ter resultado em teor elevado de FDN e efeito negativo no CMS (Figura 2).

Utilizando farelo de glúten de milho na forma úmida em níveis superiores a 50\% da MS na ração de vacas leiteiras, Staples et al. (1984) e Fellner et al. (1988) observaram redução no consumo de MS, fato atribuído ao aumento do teor de FDN da ração. Neste estudo, apesar da redução no consumo de MS com a maior inclusão de $\mathrm{PC}$ na ração, o consumo de FDN (Figura 2) não diferiu entre as rações com PC. 
Apesar do aumento numérico, a substituição de $50 \%$ do milho por PC elevou o GPD $(1,59$ x $1,72 \mathrm{~kg} / \mathrm{dia}$, respectivamente). Em rações com 50\% (Prado et al., 2000) e 20\% (Henrique et al., 2004) de silagem de milho, a substituição de milho por PC não afetou o GPD dos animais em terminação, sugerindo que o valor energético da $\mathrm{PC}$, quando combinada com milho (50:50), é subestimado pelo NRC (1996) e NRC (2001), visto que a associação destes ingredientes pode resultar em aumentos no ganho de peso dos animais.

Sugeriu-se que a ausência de efeito positivo da PC no consumo de MS quando $50 \%$ do milho foi substituído por este ingrediente poderia ser indicativo de que o $\mathrm{pH}$ ruminal proporcionado pela ração com milho foi satisfatório. Desse modo, seria difícil explicar o aumento em GPD dos animais neste caso. Uma possível explicação seria embasada em alguns estudos nos quais o efeito benéfico no $\mathrm{pH}$ ruminal não necessariamente aumentou a IMS (Santos et al., 2001; Nussio et al., 2002) com a substituição do milho por polpa cítrica peletizada em rações para vacas em lactação. Possivelmente, houve melhora na digestibilidade da ração e aumento no aporte de energia para o animal, sem aumento na CMS. Outra explicação seria o possível efeito benéfico na sincronização da degradação ruminal entre proteína e energia quando há uma combinação de fontes de carboidratos de alta digestibilidade ruminal. Neste caso, ocorre a combinação de amido, açúcares, pectina e fibra de alta digestibilidade, em vez da predominância de apenas uma dessas fontes. Experimentos sobre metabolismo que comprovem estas hipóteses não foram encontrados na literatura.

Em comparação à ração com 50\% de $\mathrm{PC}$, rações com 75 e $100 \%$ causaram redução linear $(\mathrm{P}<0,05)$ no GPD $(1,72$ x 1,55 $\mathrm{x} 1,48 \mathrm{~kg} / \mathrm{d}$ ) dos animais, o que, provavelmente, foi ocasionado pela redução linear no CMS nessas rações $(10,85 \mathrm{x}$ $10,39 \times 9,78 \mathrm{~kg} / \mathrm{d})$

Estudos realizados na década de 70 com rações ricas em cana-de-açúcar para bovinos comprovaram que o consumo de MS e o GPD são aumentados significativamente com a

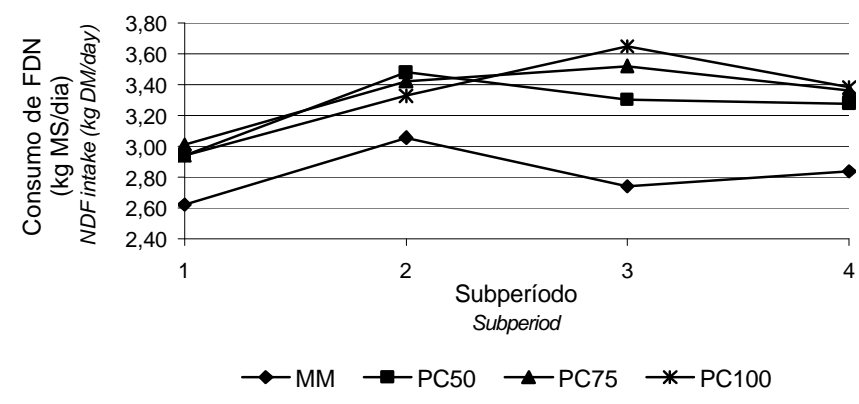

Figura 2 - Consumo de FDN durante o experimento. Figure 2 - NDF intake during the experiment. suplementação com pequenos níveis de concentrado contendo proteína e amido não degradáveis no rúmen. Segundo Leng \& Preston (1976), o uso de cana-de-açúcar como volumoso seria limitado pelo suprimento de aminoácidos (proteína) e glicose (amido) pós-rúmen de origem alimentar, o que resultaria em diminuição no consumo de MS. Preston et al. (1976) utilizaram níveis crescentes de farelo de polidura de arroz (0,4 a 1,2 kg/animal/dia) para novilhos alimentados com cana-de-açúcar, melaço e uréia e observaram aumento linear da CMS e do GPD. Em experimento realizado por Montepellier \& Preston (1977), o mesmo comportamento foi observado, pois a adição de $0,5 \mathrm{~kg} /$ animal/dia de farelo de arroz à ração praticamente dobrou $\mathrm{o}$ consumo de MS em comparação ao fornecimento exclusivo de cana-de-açúcar. Apesar da redução drástica no consumo de MS e no GPD na ração com $100 \%$ de substituição do milho por PC (teor de amido muito baixo, quase nulo), os valores de CMS e GPD não foram baixos. O GPD de 1,48 kg/dia é considerado satisfatório para animais em terminação.

A redução da necessidade e da proporção adequada de amido no intestino delgado que deve ser absorvida como glicose tem sido discutida (Nocek \& Tamminga, 1991). Resultados de experimentos realizados nos últimos 20 anos com implante de cateteres em animais para avaliação do metabolismo pós-absortivo têm comprovado que os tecidos viscerais drenados pela veia porta, como rúmen e intestinos, são ávidos por energia, especialmente glicose (Huntington, 1997; Reynolds, 2002). O fluxo líquido de glicose na veia porta em bovinos em terminação é normalmente zero ou negativo, em decorrência do uso intenso deste nutriente pelos tecidos do trato gastrointestinal. A necessidade ou não de amido no intestino delgado, que deve ser absorvido como glicose, tem sido discutida (Reynolds, 2002).

A eficiência alimentar foi maior $(\mathrm{P}<0,10)$ com a ração com $50 \%$ de PC, em comparação àquela com $100 \%$ de milho. Teores crescentes de PC na ração (75 e 100\% de PC) não afetaram $(\mathrm{P}>0,05)$ a eficiência alimentar em comparação à ração com 50\% de PC. Apesar da redução na CMS e no GPD nos animais alimentados com a ração com $100 \%$ de PC, em comparação àquelas com 50 e 75\%, a eficiência alimentar não foi influenciada pelos níveis de PC.

Henrique et al. (2004) trabalharam com garrotes Santa Gertrudes e forneceram teores crescentes de PC nas rações (0, 25, 40 e 55\% da MS) em substituição ao milho moído e não observaram diferença na eficiência alimentar dos animais. Os dados deste estudo e os de Henrique et al. (2004) indicam que o NRC (1996) e o NRC (2001) subestimam o valor energético da PC. Destaca-se ainda que açúcares, pectina 
e fibra de alta digestibilidade, quando combinados, como na PC, substituíram o amido de milho sem prejudicar a eficiência alimentar de bovinos em terminação.

Na Figura 3 é ilustrada a tendência de deposição de gordura nos tourinhos Canchim utilizados neste experimento. Não houve efeito dos níveis de substituição do milho por PC na espessura de gordura subcutânea ao final do experimento. Os animais começaram a acumular gordura de forma significativa a partir do último período - o que explica a diminuição no GPD nesta fase -e atingiram 3,0 mm de gordura subcutânea no músculo Longissimus dorsi aos $490 \mathrm{~kg}$ de PV.

Os valores obtidos para o rendimento de carcaça foram homogêneos, comprovando que esta característica não foi influenciada pelos níveis de substituição do milho por PC. No trabalho de Prado et al. (2000), a substituição do milho (40, 60, 80 e $100 \%$ ) por PC em rações com $50 \%$ de silagem de milho e 50\% de concentrado para bovinos mestiços (Nelore x Angus) terminados com 20 meses de idade não afetou a espessura de gordura e o rendimento de carcaça $(57 \%)$.

Henrique et al. (1998), em estudo com tourinhos Santa Gertrudes, avaliaram a substituição do milho moído por PC em rações com $20 \%$ de silagem de milho e não observaram diferenças no rendimento de carcaça e na espessura de gordura entre as fontes testadas. Henrique et al. (2004), no entanto, observaram, em tourinhos Santa Gertrudes, menor deposição de tecido adiposo com o aumento dos níveis de PC nas rações (7,0; 6,0; 5,3 e 4,7 mm de gordura subcutânea para $0,25,40$ e $55 \%$ de PC na MS, respectivamente). Contudo, os autores consideraram que, em todos os tratamentos, as espessuras de gordura foram suficientes para boa proteção de carcaça.

Neste estudo, a combinação de MM e PC em partes iguais aumentou $(\mathrm{P}<0,10)$ a concentração de EL de mantença em $5,78 \%$ e a de ganho em $8,11 \%$, em comparaçãoao fornecimento de MM exclusivo (Tabela 4). Esta diferença entre as rações com 0 e $50 \%$ de $\mathrm{PC}$ sugere que o valor energético da PC, em comparação ao do milho moído fino, foi subestimado pelo NRC (1996) e pelo NRC (2001). Entretanto, os valores de EL observados para o MM foram bem inferiores ao esperado (Tabela 4). No caso da PC, os valores observados foram mais próximos ao esperado.

Como demonstrado na Tabela 4, os valores de $\mathrm{EL}_{\mathrm{m}}$ observados para as rações, calculados de acordo com fórmulas propostas por Zinn \& Shen (1998), foram inferiores aos esperados. Os valores observados de EL de manutenção e de ganho inferiores ao esperado podem ser conseqüência de um valor energético real da silagem de cana-de-açúcar inferior ao estimado pelo NRC (2001), de 61\% de NDT. Pedroso et al. (2004) obtiveram valores de 55 e $58 \%$ de NDT para a silagem de cana-de-açúcar.

No presente estudo, a silagem de cana-de-açúcar compôs $30 \%$ da ração. É possível que a digestão de sua fração fibrosa tenha sido prejudicada por um ambiente ruminal inadequado. Isto explicaria os valores observados mais baixos de energia na ração exclusiva de milho, em comparação às rações contendo polpa cítrica. Rações com alto teor de amido podem resultar em ambiente ruminal menos favorável à digestão de fibra quando comparadas com rações ricas em pectina e fibra de alta digestibilidade proporcionadas pela polpa cítrica.

Se utilizado o valor sugerido por estes autores, de 58\% de NDT para a silagem de cana-de-açúcar, na simulação de energia esperada no NRC (1996), o valor para a relação observado:esperado é próximo de 1. A revisão de Pedroso et al. (2004) apresentou valor de 44\% de NDT para silagem de cana-de-açúcar do tratamento MM do presente estudo, atribuído ao alto valor energético do milho presente nesta ração. Este resultado explicaria o valor mais próximo de 1 para a relação energia observada:esperada nas rações com $\mathrm{PC}$ e a diferença entre as rações com $0 \mathrm{e} 50 \%$ de $\mathrm{PC}(\mathrm{P}<0,05)$. Nas rações com $\mathrm{PC}$, o $\mathrm{pH}$ ruminal pode ter sido menos crítico para a digestão ruminal da silagem de cana que na ração isenta de $\mathrm{PC}$.

Pelo método de substituição apresentado por Zinn et al. (2002), foi calculada a EM da PC. Segundo o NRC (1996), a PC possui NDT $8,9 \%$ menor que o MM ( 82 vs $88 \%$ de NDT). Entretanto, pelos cálculos de EM obtidos neste estudo, pelo método da substituição (Zinn et al., 2002), o valor da $\mathrm{PC}$ foi $6,25 \%$ maior que o do MM. Considerando o valor estimado de EM do milho (3,19 Mcal $/ \mathrm{kg}$ de MS), calculado segundo as fórmulas do NRC (1996) com base no NDT estimado pelo NRC (2001), os valores de EM observados para a PC seriam de 3,39 Mcal/kg de MS na ração com

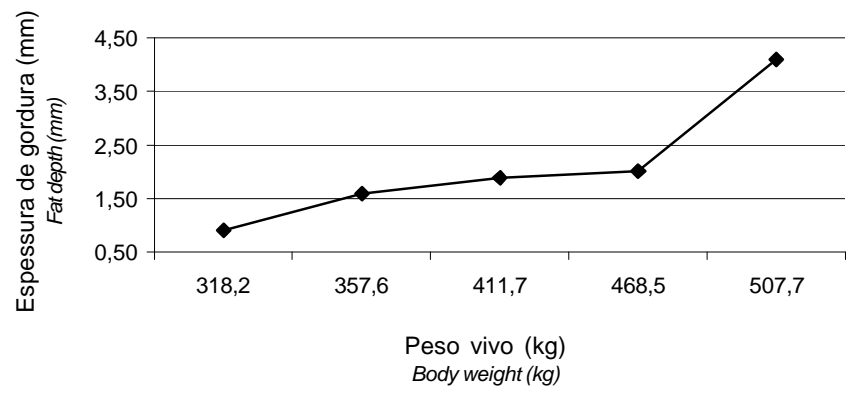

Figura 3 - Deposição de gordura em tourinhos Canchim Figure 3 - Fat deposition in Canchim yearling bulls. 
Tabela 4 - Energia líquida das rações

\begin{tabular}{|c|c|c|c|c|}
\hline \multirow[t]{2}{*}{ Item } & \multicolumn{3}{|c|}{$\begin{array}{c}\text { Nível de substituição, \% } \\
\text { Proportion of dried } \\
\text { citrus pulp, } \%\end{array}$} & $\begin{array}{c}\text { EPM } \\
S E M\end{array}$ \\
\hline & 0 & 75 & 100 & \\
\hline
\end{tabular}

EL observada da ração, Mcal/kg

Dietary net energy, Mcal/kg

$\begin{array}{lccccc}\begin{array}{l}\text { Manutenção } \\ \text { Maintenance }\end{array} & 1,73 & 1,83 & 1,76 & 1,78 & 0,040 \\ \begin{array}{l}\text { Ganhob } \\ \text { Gain }\end{array} & 1,11 & 1,20 & 1,13 & 1,15 & 0,036 \\ \end{array}$

EL da ração, observado:esperado

Observed/expected dietary net energy

$\begin{array}{lccccc}\text { Manutenção }^{\mathrm{a}} & 0,81 & 0,90 & 0,90 & 0,93 & 0,029 \\ \begin{array}{l}\text { Maintenance } \\ \text { Ganho }^{\mathrm{a}}\end{array} & 0,88 & 1,00 & 1,00 & 1,05 & 0,044 \\ \text { Gain } & & & & \end{array}$

Gain

a 0 vs $50 \%$ de $P C, P<0,05$

b 0 vs $50 \%$ de $P C, P<0,10$.

$50 \%$ de PC, de 3,25 Mcal $/ \mathrm{kg}$ de MS na ração com $75 \%$ de PC e 3,26 Mcal/kg de MS naquela com $100 \%$ de PC. Com base nos valores de EM obtidos, o NDT da PC neste experimento variou de 90 a 93,7\% da MS e foi superior ao descrito pelo NRC (1996), de 82\%. Ressalta-se novamente que este valor energético elevado estimado para a PC pode estar diretamente relacionado ao provável efeito benéfico deste alimento no ambiente ruminal, o que favoreceu a fermentação da porção fibrosa da silagem de cana-de-açúcar em comparação ao milho moído, rico em amido. Isso explica o maior GPD e a melhor eficiência alimentar obtidos com a ração com $50 \%$ de $\mathrm{PC}$, comparada àquela com milho exclusivamente. Os valores de NDT estimados para a PC entre 90 e $93,7 \%$ podem não ser reais. Caso o valor energético da silagem de cana-de-açúcar tenha realmente variado entre a ração exclusiva com milho e as rações com polpa, devido ao ambiente ruminal, a estimativa do valor energético da PC pelo método da substituição não é válida.

Como o valor de EM na ração com $50 \%$ de PC foi superior ao encontrado nas demais (75 e 100\% de PC), é possível que esta porcentagem de substituição seja um ponto de otimização biológica, tendo em vista as interações associativas entre as diferentes fontes de carboidratos.

\section{Conclusões}

Para bovinos em terminação alimentados com rações com $70 \%$ de concentrado e $30 \%$ de silagem de cana-deaçúcar, a polpa cítrica tem valor energético superior ao milho moído quando substitui $50 \%$ e valor energético similar quando substitui 75 ou $100 \%$ do milho.

Quanto maior o nível de inclusão de PC (acima de 50\%), menor foi o CMS e mais baixo o GPD (sem alteração na eficiência alimentar). As características de carcaça avaliadas neste experimento não foram alteradas pelos níveis de substituição do milho por polpa cítrica.

Em rações com $70 \%$ de concentrado para bovinos em terminação, os valores relativos de energia das rações com PC, em comparação ao valores de enrgia da ração contendo milho moído, são subestimados pelo NRC (1996, 2001).

Bovinos de corte em terminação apresentam bom desempenho quando alimentados com rações com teores mínimos ou quase nulos de amido quando outros carboidratos de alta degradabilidade ruminal são fornecidos, como no caso de rações com PC.

\section{Literatura Citada}

ASSOCIATION OF OFFICIAL ANALYTICAL CHEMISTS - AOAC. Official methods of analysis. 15.ed. Arlington: 1990. v.1, $1117 \mathrm{p}$.

CHESSON, A.; MONRO, J. Legume pectin substances and their degradation in the ovine rumen. Journal of Science Food Agricultural, v.33, p.852, 1982.

FEGEROS, K.G.; ZERVAS, S.; STAMOULI, E. et al. Nutritive value of dried citrus pulp and its effects on milk yield and milk composition of lactating ewes. Journal of Dairy Science, v.78, p.1116-1121, 1995.

FELLNER, V.; BELYEA, R.L.; STEEVENS, B.J. et al. Nutritive value and feeding management of corn gluten feed. Journal of Animal Science, v.71, p.215, 1988

HENRIQUE, W.; LEME, P.R.; LANNA, D.P.D. et al. Substituição de amido por pectina em dietas com diferentes níveis de concentrado. 1. Desempenho animal e características de carcaça. Revista Brasileira de Zootecnia, v.27, n.6, p.1206$1211,1998$.

HENRIQUE, W.; SAMPAIO, A.A.M.; LEME, P.R. et al. Desempenho e características da carcaça de tourinhos Santa Gertrudes confinados, recebendo dietas com alto concentrado e níveis crescentes de polpa cítrica peletizada. Revista Brasileira de Zootecnia, v.33, p.463-470, 2004.

HUNTINGTON, G.B. Starch utilization by ruminants: from basics to the bunk. Journal of Animal Science, v.75, p.852-867, 1997.

LAWRENCE, T.L.J.; FOWLER, V.R. Compensatory growth. In: LAWRENCE, T.L.J.; FOWLER, V.R. (Eds.) Growth of farm animals. Oxon: CAB International, 1997. p.219-245.

LENG, R.A.; PRESTON, T.R. Sugar cane for cattle production: present constraints, perspectives and research priorities. Tropical Animal Production, v.1, p.1-22, 1976.

MONTEPILLIER, F.A.; PRESTON, T.R. Digestibility and voluntary intake on sugar cane diets: effects of chopping the cane stalk in particles of different sizes. Tropical Animal Production, v.2, p.40-43, 1977.

NATIONAL RESEARCH COUNCIL - NRC. Nutrient requirements of beef cattle. 6.ed. Washington, D.C.: National Academy Press, 1984. 381p.

NATIONAL RESEARCH COUNCIL - NRC. Nutrient requirements of dairy cattle. 6.ed. Washington, D.C.: National Academy Press, 1989. 248p. 
NATIONAL RESEARCH COUNCIL - NRC. Nutrient requirements of beef cattle. 7.ed. Washington, D.C.: National Academy Press, 1996. 242p.

NATIONAL RESEARCH COUNCIL - NRC. Nutrient requirements of dairy cattle. 7.ed. Washington: National Academy Press, 2001. 408p.

NOCEK, J.E.; TAMMINGA, S. Site of digestion of starch in the gastrointestinal tract of dairy cows and its effect on milk and composition. Journal of Dairy Science, v.74, p.3598, 1991.

NUSSIO, C.M.B.; SANTOS, F.A.P.; PIRES. A.V. et al. Fontes de amido de diferentes degradabilidades e sua substituição por polpa de citrus em dietas para vacas leiteiras. Acta Scientiarum, v.24, n.4, p.1079-1086, 2002.

PEDROSO, A.F.; SCHMIDT, P.; NUSSIO, L.G. Silagem de cana-deaçúcar no confinamento de bovinos. In: SIMPÓSIO SOBRE BOVINOCUlTURA DE CORTE, 5., 2004, Piracicaba. Anais... Piracicaba: Fundação de Estudos Agrários "Luiz de Queiroz", 2004. p. 243-259.

PERKINS, T.L.; GREEN, R.D.; HAMLIN, K.E. et al. Ultrasonic prediction of carcass merit in beef cattle evaluation of technician effects on ultrasonic estimates of carcass fat thickness and longissimus muscle area. Journal of Animal Science, v.70, p.2758-2765, 1992 .

PRADO, I.N.; PINHEIRO, A.G.; ALCALDE, C.R. et al. Níveis de substituição do milho pela polpa de citrus peletizada sobre o desempenho e características de carcaça de bovinos mestiços confinados. Revista Brasileira de Zootecnia, v.29, p.21352141, 2004

PRESTON, T.R.; CARCAÑO, C.; ALVAREZ, P.F. et al. Tropical Animal Production, v.1, p.150-62, 1976.

REYNOLDS, C.K. Economics of visceral energy metabolism in ruminants: Toll keeping or internal revenue service. Journal of Animal Science, v.80, p.E74-E84, 2002 (suppl. 2)

SANTOS, F.A.P.; MENEZES JR., M.P.; SIMAS, J.M.C. et al. Processamento do grão de milho e sua substituição parcial por polpa de citros peletizada sobre o desempenho, digestibilidade de nutrientes e parâmetros sangüíneos. Acta Scientiarum, v.23, n.4, p.923-931, 2001.

SANTOS, F.A.P.; PEREIRA, E.M.; PEDROSO, A.M. Suplementação energética de bovinos de corte em confinamento. In: SIMPÓSIO SOBRE BOVINOCUlTURA DE CORTE, 5., 2004, Piracicaba. Anais... Piracicaba: Fundação de Estudos Agrários "Luiz de Queiroz”, 2004.p.261-297.
STATISTICAL ANALYSIS SYSTEM - SAS. User's guide: statistics. Cary: 1999. 965p.

SILVA, D.J.; QUEIROZ, A.C. Análise de alimentos: métodos químicos e biológicos. 3.ed. Viçosa, MG: Editora UFV, 2002. $235 \mathrm{p}$.

SNIFFEN, C.J. Balancing rations for carbohydrates for dairy cattle. In: FEED DEALER SEMINARS, 1988, Ithaca. Proceedings... Ithaca: Cornell Cooperative Extension, 1988. n.112, p.9-19.

STAPLES, C.R.; DAVIS, C.L.; Mc COY, G.C. et al. Feeding value of wet corn gluten feed for lactating dairy cows. Journal of Dairy Science, v.67, p.1214, 1984.

THEURER, C.B.; LOZANO, O.; ALIO, A. et al. Steam-processed corn and sorghum grain flaked at different densities alter ruminal, small intestinal, and total tract digestibility of starch by steers. Journal of Animal Science, v.77, p.2824-2831, 1999.

Van SOEST, P.J.; ROBERTSON, J.B.; LEWIS, B.A. Methods for dietary fiber, neutral detergent fiber, and nonstarch polysaccharides in relation to animal nutrition. Journal of Dairy Science, v.74, p.3583-3596, 1991.

Van SOEST, P.J. Nutritional ecology of ruminant. Ithaca: Comstock Publishing Associations, 1994. 476p.

WEISS, W.P.; CONRAD, H.R.; PIERRE, R.S. A theoretically-base model for predicting total digestible nutrient values of forages and concentrates. Animal Feed Science and Technology, v.39, p.95-119, 1992.

YU, P.; HUBER, J.T.; SANTOS, F.A.P. et al. Effects of ground, steam-flaked, and steam-rolled corn grains on performance of lactating cows. Journal of Dairy Science, v.81, p.777-783, 1998.

ZINN, R.A.; SHEN, Y. An evaluation of ruminally degradable intake protein and metabolizable amino acid requirements of feedlot calves. Journal of Animal Science, v.76, p.1280-1289, 1998.

ZINN, R.A.; OWENS, F.N.; WARE, R.A. Flaking corn: processing mechanics, quality standards, and impacts on energy availability and performance of feedlot cattle. Journal of Animal Science, v.80, p.1145-1156, 2002. 